\title{
Coastal Sediment Transport along Kalpakkam using Sediment Trend Exploaration and Numerical Modelling
}

\author{
Susmitha Thankachan, A S Kiran, Vijaya R, Suriyakala C D
}

\begin{abstract}
The impact of coastal sediment transport in the nearshore region is significant and the need for improved sediment quantification techniques appears to be universally accepted. The coastal sediment transport models presently in use were derived empirically from very sparse measurements of waves and currents and from laboratory experiments.

The shoreline of Kadalur fishing villages near Kalpakkam has been experiencing erosion due to occurrence of cyclones every monsoon. Palar River with its confluence in the Bay of Bengal at the northern tip of the Kadalur villages has its mouth closed due to negligible river flow. The purpose of this study is to assess sediment dynamics in the Kalpakkam coast using two independent approaches; namely Sediment Trend Analysis (STA) and two dimensional numerical modelling. The latter can track the movement of individual particles. Numerical modelling approach is based on Delft3D model which allows the coupling of flow and wave modules. STA and numerical modelling results can provide sediment transport direction. The combination of both approaches provides a means of verification of sedimentation processes.

The basic assumption in STA is that sediment transport can be responsible for the differences in sediment grain size distributions. For Grain Size Trend Analysis, grab samples were collected throughout the nearshore area. Grain Size Trend Analysis was then carried out and subsequent results were plotted to obtain the sediment transport pattern for the region. The results obtained are compared with the numerical model results and also used for validation of sediment transport evaluated using the numerical model.
\end{abstract}

Keywords: DELFT3D, Numerical modelling, Sediment transport, Sediment Trend Analysis

\section{INTRODUCTION}

The coast can be characterised due to the fact the area in which land and water meet. The seashore location is of variable width and moreover modifications

Overhauled Manuscript received on December 22, 2018.

Susmitha Thankachan, college of Ocean Engineering and Underwater technology, Kerala college of Fisheries and Ocean research, Kochi, India, sush.Thankachan@gmail.Com

A S Kiran, Coastal and Environmental Engineering, countrywide Institute of Ocean era, Chennai, India,

Revised Version Manuscript Received on 10, September 2019.

Susmitha Thankachan, Pursuing M.tech in Coastal and Harbour Engineering from Kerala University of Fisheries and Ocean Studies, Kochi., Kerala, India.

A S Kiran, Scientist D a National Institute of OceanTechnology, Chennai, Tamil Nadu, India.

Dr. Vijaya Ravichandran, Scientist-F, Coastal \& Environmental Engineering Group,NIOT Chennai, Tamil Nadu, India.

Dr. Suriyakala C D, Student, School of Bio-Engineering, Dept. of Genetic Engineering, Bharath Institute of Higher Education and Research, Chennai, Tamil Nadu, India.

\section{kiran@ niot.Res.In}

Vijaya R., Coastal and Environmental Engineering, national Institute of Ocean era, Chennai, India, vijaya@niot.Res.In

Suriyakala C D, college of Ocean Engineering and Underwater era, Kerala college of Fisheries and Ocean studies, Kochi, India, drcdsk@yahoo.In

with yr or seasons. there may be a everyday connection among land and water media that portray the seaside scenario. Waves stepping into the shallow water revel in changes, as an example, reflections, refractions, shoaling, diffraction and breaking. Longshore cutting-edge-day produced with the useful resource of the breaking waves are responsible for shifting the silt alongside the surf-zone [1]. The research of sea shore factors is one of the remarkable territories of studies for expertise the morphology in every advocate. The research is huge in light of the reality that the impacts of tides, waves and flows continuously alter landform includes in a quick period. The sedimentological concentrates offer critical data approximately the idea of sea shore and its factors on depositional state of affairs [2].

Silt transport is because of the development of sturdy particles, and this can be activated by means of the development of the liquid in which the dregs is entrained and furthermore due to gravity following up at the residue. Residue shipping takes area in feature frameworks in which the particles are clastic rocks, dirt or dust; and the liquid is air, water or ice; and the strength of gravity acts to transport the debris alongside the slanting ground on which they'll be resting. Residue delivery due to clean movement takes area in streams, lakes, oceans and seas and brilliant water our our our bodies due to ebbs and flows and tides. Silt shipping because of gravity may be determined for the most element on slopes, slanting surfaces, bluffs and mainland rack. Ice sheets likewise assume a big undertaking within the car of residue given that they motion entangling silt with them. Wind is also a large problem influencing silt delivery along earthly surfaces.

Residue delivery research are fundamental for finding out the degree of disintegration or gradual addition with time and separation over which it takes location. The residue can be moved starting with one spot then onto the subsequent as suspension, bed load, and so forth [3].

This paper talks about residue shipping thinks

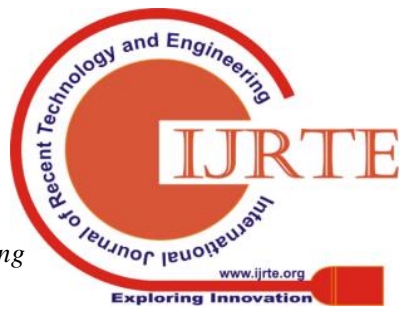


approximately along Kalpakkam coast to decide the internet dregs shipping heading in that locale and furthermore to take a look at one-of-a-type additives and systems influencing the disintegration or growth within the territory

\section{A. Background}

Kalpakkam is located in the east coast of India, situated $70 \mathrm{~km}$ south of Chennai in Kanchipuram district. Kanchipuram has been affected by higher number of severe cyclones in the past decade.

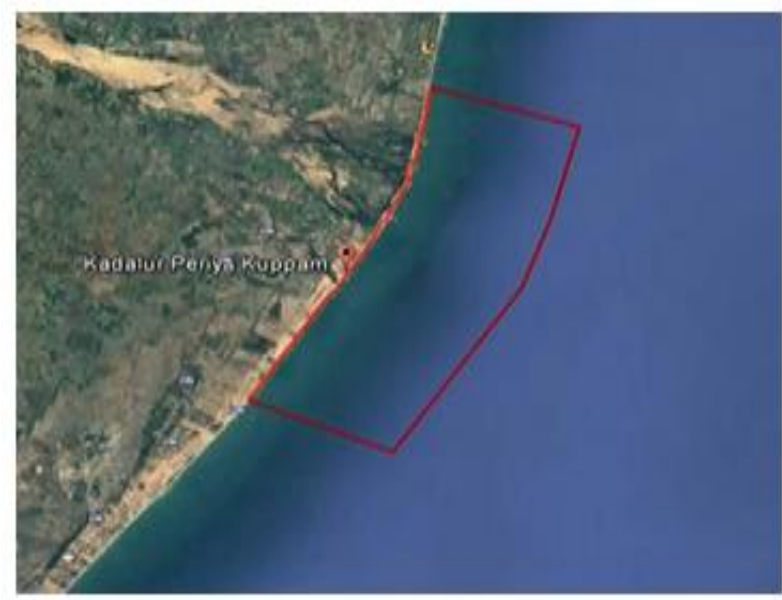

Fig.1 look at territory (deliver: Google Earth)

The exam vicinity consists of a coastline period of $25 \mathrm{~km}$. Kalpakkam is having a at once shoreline with direction in top east southwest bearing. at the coast the rise is $5 \mathrm{~m}$ over the imply ocean degree which slowly increments to $100 \mathrm{~m}$ above imply ocean degree as it arrives at $100 \mathrm{~km}$ over the coast

\section{SEDIMENT FASHION ANALYSIS}

using dregs sample examination, an research on residue delivery technique has been finished. The hypothesis at the back of dregs sample research modified into first dispensed through manner of McLaren and Bowles in 1985. The essential supposition in residue pattern exam (STA) is that silt delivery may be answerable for the differences in dregs grain size disseminations. for this reason as dregs moves alongside a pathway, its grain period dissemination may alternate [4]. STA is a kinematic model wherein the conduct of silt debris is depicted no matter the technique [5]. In comparison with dynamic showing, kinematic demonstrating is straightforward and substances progressively ok facts in regards to silt the board troubles. in no way like extraordinary approaches used to decide silt transport like geomorphological notion, tracers, in-situ estimations

moreover, numerical demonstrating, STA gave a superior comprehension of the deliver and development of silt [6]. Dregs sample studies is actually not a numerical model, but an observational approach in which examples of silt shipping is gotten from the changes inside the grain length circulate of residue. STA method uses contrasts in grain length disseminations of ocean mattress clutch tests collected on an regular framework. on this approach grain length patterns that have been recognized from the accumulated surficial examples are changed into lingering vectors that communicate to the internet silt transport instance and regions of disintegration, slow addition and dynamic

stability. STA also can supply an device to higher comprehension of positive disintegration and growth examples have for areas in which silt pathways are not in reality stated.For Grain length trend evaluation about 500 seize assessments were accumulated at a few level in the nearshore territory from December 2012 to January 2018. Grain length parameters, for example, imply grain period, skewness and arranging coefficient of the examples have been resolved the usage of lab studies and laptop application. This software is carried out for the research of grain period measurements, for example, mean, skewness, mode, arranging and one-of-a-kind insights. The records record required for this software application to be able to build up grain length insights is mass or level of residue hung on sifter set at any interims at some point of strainer length investigation [7]. Grain length insights are determined mathematically and geometrically in metric gadgets just as logarithmically in phi devices utilising minute and folk and Ward graphical techniques [8]. The chart portraying grain period insights is seemed (Fig. 2). Grain length trend assessment (GSTA) come to be then finished the usage of FORTRAN software. It characterizes residue shipping sample vectors via searching at the grain period parameters of any reading stations. statistics records for GSTA had been all out quantity of attempting out stations $(\mathrm{N})$, scaling problem for $\mathrm{X}$ data $(\mathrm{An})$, reading station numbers, trademark separation (DC), grain length parameters and position of examining stations [9]. consequently via the use of FORTRAN software program greatness

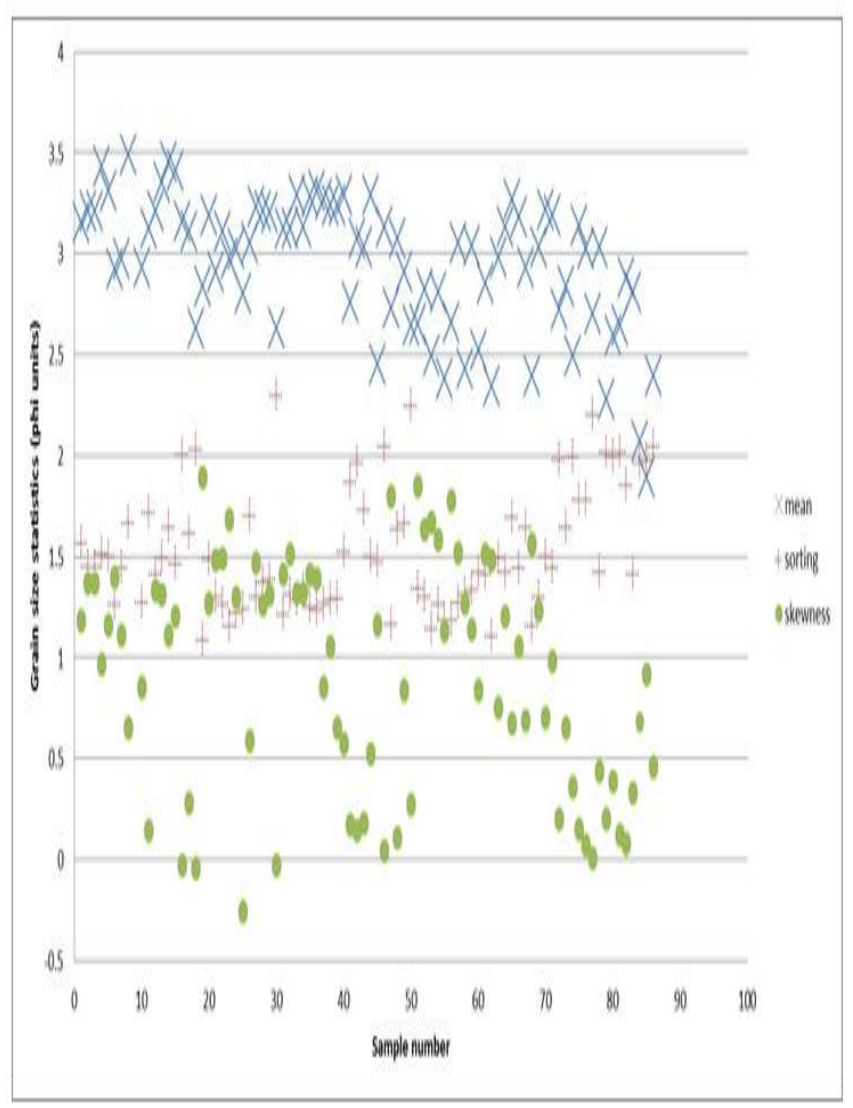

Fig. 2 Grain Size Statistics 

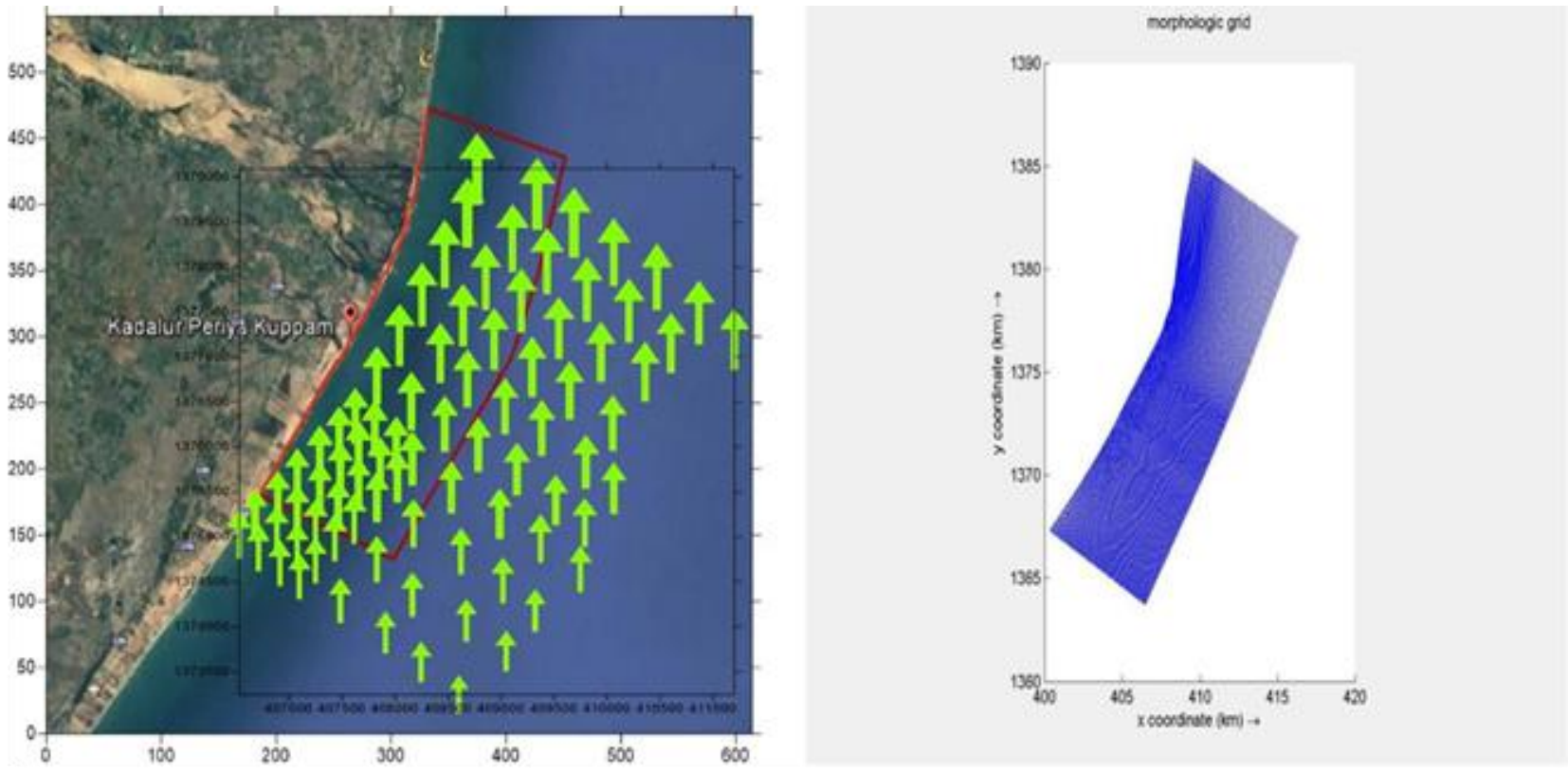

Fig.3 Net sediment transport for the month of June

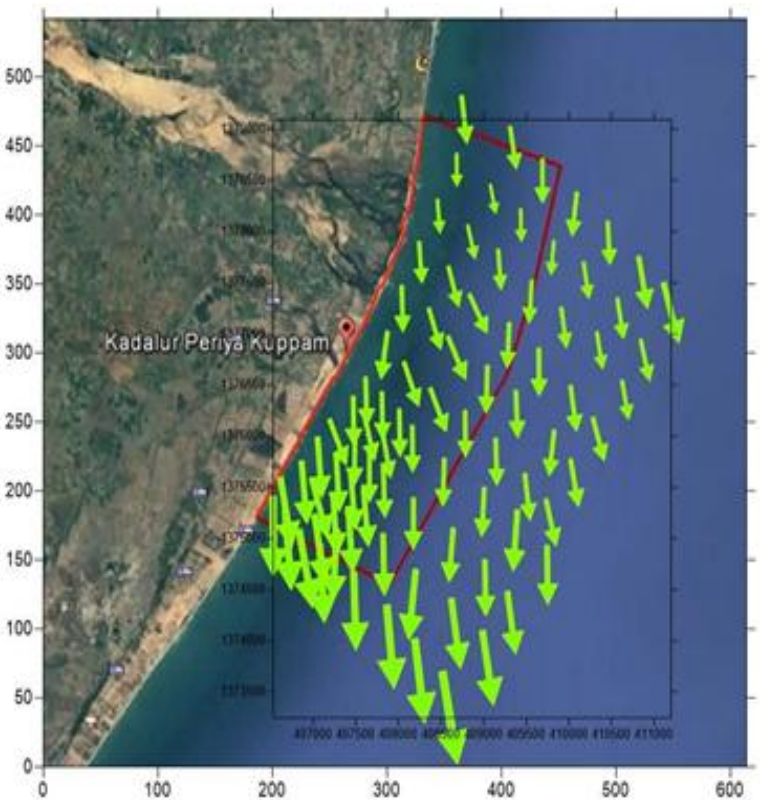

Fig.4 net dregs delivery for the lengthy stretch of January

what is more, bearing of lingering vectors had been gotten. Consequent effects have been plotted using programming package deal SURFER to accumulate the silt transport layout at some diploma in the lengthy durations of June and January for the region

Aftereffects of STA along the complete beach territory are dissected and in line with the notion, the bearing of shipping inside the direction of the lengthy stretch of June is from south to north as appeared in Fig 3 and towards south in the path of the lengthy durations of January as regarded in Fig.four. This very last effects fits with the silt delivery in east shore of India. The effects were given are contrasted and the numerical version consequences and furthermore carried out in approval of dregs transport assessed utilising the numerical model

\section{NUMERICAL VERSION \& RESULTS}

Silt delivery paperwork at Kalpakkam coast end up tested utilising programming bundle deal known as Delft3D, is a numerical version containing style of included modules. The Delft3D WAVE module changed into executed to reenact the age of wind produced waves in beach the the front waters. For a given base geology wave module of Delft3D registers wind produced waves, wave engendering and nonlinear wave-wave association and dissemination [10]. It moreover figures wind concern, water stage, and glide location in profound, shallow and restricted profundities of water. Delft3D-float is a hydrodynamic module that could be a multi-dimensional (2nd or 3-D) and shipping challenge utility which figures nonsteady move and shipping wonders that final consequences from tidal and meteorological the use of on a rectilinear or a curvilinear, restrict ready lattice [11]. In curvilinear co-ordinates, the loose floor diploma and bathymetry are recognized with a level even plane of reference, despite the fact that in round co-ordinates the reference plane pursues the Earth's arch. For the calculation of morphological response of the coast Delft3D drift module is mixed with DELFT3d WAVE MODULE on the internet. WAVE and float modules are coupled on-line at ordinary meantime to offer the impact of wave on go together with the flow and therefore for wave change motion restrict conditions are given. Dregs transport under consolidated waves and contemporary are registered the use of shift in climate conditions dissemination circumstance. The dregs transport and morphology modules represent bed and suspended burden shipping of agency and noncohesive residue and for the shopping for and selling of silt most of the 
For this showing cause, shoreline is taken from the google earth satellite tv for $\mathrm{pc}$ tv for $\mathrm{pc}$ photograph from which the land restrict report is made. this is despatched out to international mapper programming that permits you to exchange over land restrict into Delft $3 d$ design. The coastline of 2017 is utilized for the development of land restrict report.

The model consists of only one domain as shown in Fig.5. Domain grid has a dimension of $25 \mathrm{~km} \times 10 \mathrm{~km}$. Nearshore area is provided with finer grid $(30 * 30)$ since the sediment transport is predominant in this area, with a coarse grid

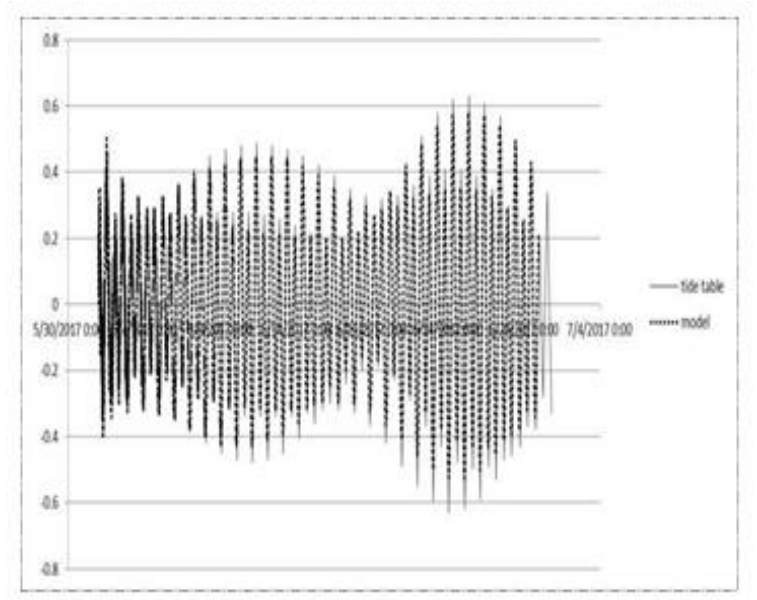

Fig. 6 Tide validation

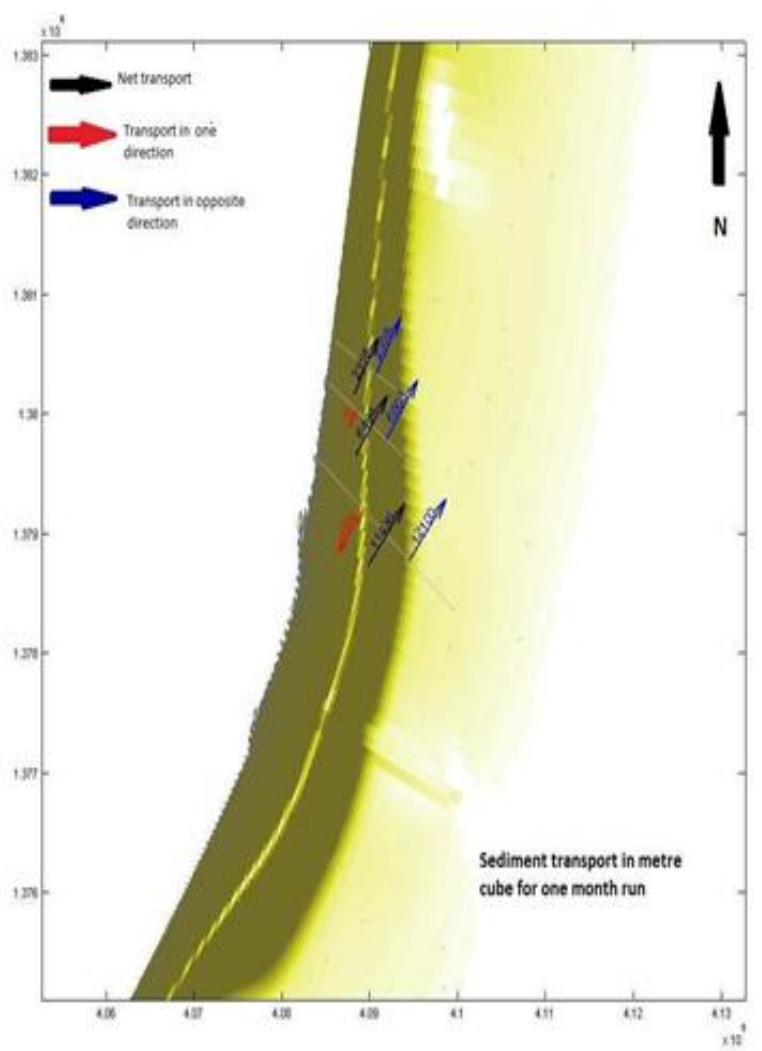

Fig. 7 DETRAN yield for the lengthy stretch of June

seaward (100 and fifty*a hundred fifty). The bathymetry facts changed into acquired from the hydrographic assessment directed via countrywide Institute of Ocean generation (NIOT).Sediment grain length statistics is gotten from the silt checks collected from severa regions using seize sampler. At that issue grain length and explicit gravity take a mattress and the waft [12].

look at is completed at NIOT lab. Grain size records from lab exam is applied for demonstrating motive. Tidal materials of the territory had been extricated from Delft Dashboard and water degree restrict situations are applied along the boundaries. Alignment of tide end up finished the usage of tide information from tide desk. The approval results for tide showed a superb healthy that's appeared in Fig. 6. The wave contribution to the version relies upon on the estimations finished via way of NIOT alongside the open coast. results of silt shipping acquired from Delft3D have emerge as broke down using DETRAN. Yield got from Delft3D end up implemented as contribution for DETRAN.

DETRAN is a product bundle created thru Deltares for figuring out move-shore and alongside-shore dregs amount or trend. In Fig. 7, it can be observed that the net sediment

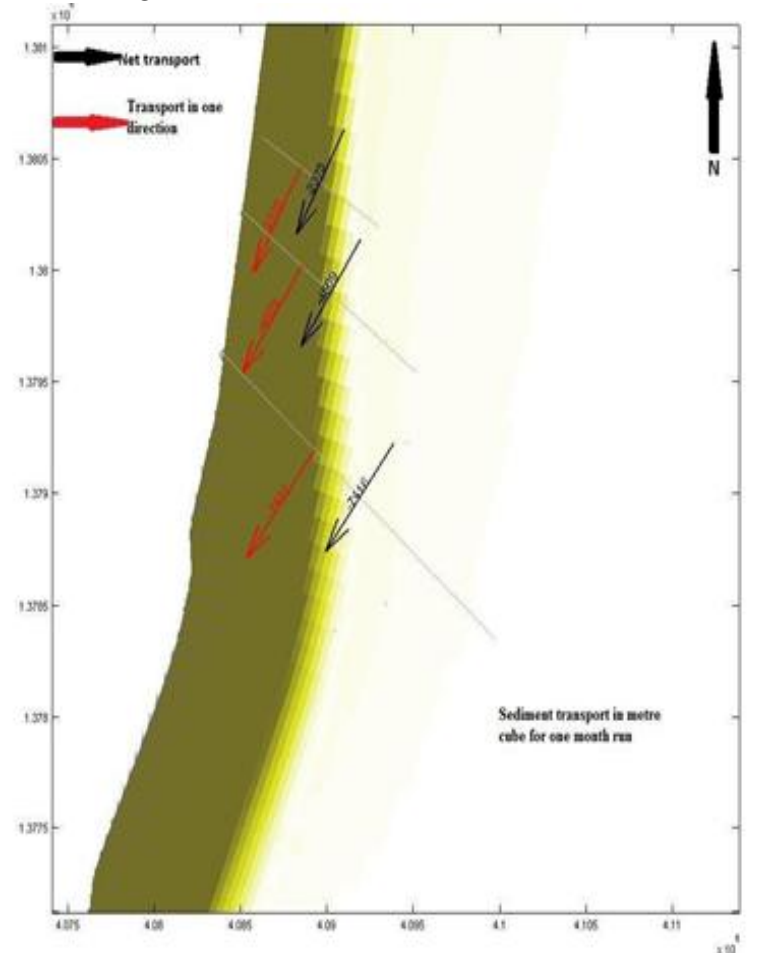

Fig. eight DETRAN yield for the prolonged stretch of January

transport at some stage in the lengthy stretch of June is from South to North and it's far closer to South finally of the duration of January (Fig. 8) which fits with the effects of beyond examination finished the usage of dregs sample studies outcomes of each 12 months silt transport along the entire seashore the front place is broke down and noticed that the heading of the car is from north to south at some point of the lengthy stretches of October to February and that in the prolonged durations of March to October it's miles from south to north. This very last outcomes suits with the dregs shipping wonders within the east monetary group of India. the ones effects have been famous with the beyond examinations.

consequently dregs transport example acquired at some degree in the exam validated a popular concurrence with the auto layout that have been gotten from silt delivery research the usage of residue sample research attempted on this locale. 


\section{END}

Silt shipping research are vital, for arranging, plan and the board of seashore the front zones. It predominantly facilities throughout the bodily procedures to have the ability to influence the development of residue in a seashore internet web page on-line. Wind created waves, trailed via tidal flows and tempest flood are the crucial medium chargeable for the seaside silt shipping. Residue shipping research are for the most element finished in waterfront the executives packages, for example, plan of seashore barrier and protection structures, beach disintegration manipulate, sea shore morphology thinks about and tremendous programs.

For analysing this, a two dimensional process based model of Delft3D was set up inconjunction with the sediment trend analysis for determining sediment transport dynamics due to fluid, tidal process and wave action in the Kalpakkam coast of Tamil Nadu. From the present study it is found that the direction of the transport is from north to south during the months of October to February and it is from south to north during the months of March to September. These results were validated with the results obtained from sediment trend analysis and found matching with the sediment transport pattern observed along east coast of India.

\section{REFERENCES}

1. Sheela Nair L, "Longshore sediment transport along the coast of Kerala in Southwest India" Procedia Engineering Volume 116, 2015, pp 40-46.

2. V Joevivek, N Chandrasekar, "Seasonal impact on beach morphology and the status of heavy mineral deposition-Central Tamil Nadu coast, India". Centre for GeoTechnology, Manonmaniam Sundaranar University, Tirunelveli, India.

3. http://coastalwiki.org

4. P. McLaren, S. H. Hill, D. Bowles, "Deriving transport pathways in a sediment trend analysis (STA)". Elsevier-Sedimentary Geology 202, 2007. pp. 489-498.

5. R. Pedreros, H.L. Howa, D. Michel, "Application of sediment trend analysis for the determination of sediment transport pathways in intertidal areas". Elsevier-Marine Geology 135, 1996. pp. 35-49.

6. McLaren, P., 2014. "Sediment trend analysis (STA): kinematic vs. dynamic modeling". Journal of Coastal Research, 30(3), pp.429-437. Coconut Creek (Florida), ISSN 0749-0208.

7. Simon J. Blott, Kenneth Pye,"GRADISTAT: A grain size distribution and statistics package for the analysis of unconsolidated sediments". Earth Surface Processes and Landforms, Earth Surf. Process Landforms 26, 1237-1248 (2001), DOI: 10.1002/esp.261

8. Patrick McLaren, R Paul Beveridge," Sediment Trend Analysis of the Hylebos Waterway: Implications for liability allocations". integrated environmental assessment and management, Vol. 2, No. 3, pp. 262-272.

9. Shu Gao, "A FORTRAN program for grain-size trend analysis to define net sediment transport pathways". Elsevier Science Ltd 1996, vol. 22, No. 4, pp. 449-452.

10. Deltares, Simulation of short-crested waves with SWAN User Manual. Version 3.04, rev. 15779, Deltares, Delft, the Netherlands, 2011.

11. Deltares, Simulation of multi-dimensional hydrodynamic flow and transport phenomena, including sediments-User Manual. Version 3.15, rev. 18392, Deltares, Delft, the Netherlands, 2011.

12. A. S. Kiran, Prince Prakash Jebakumar, Vijaya Ravichandran, Tavva Abhishek, "Detached segmented submerged breakwater made of geosynthetic tubes for kadalur periyakuppam coast, tamil nadu: a sustainable shoreline management solution". International Journal of Earth Sciences and Engineering, ISSN 0974-5904, Vol. 09, No. 6, December 2016, pp. 2688-2694.

\section{AUTHORS PROFILE}

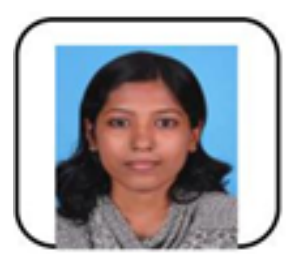

Susmitha Thankachan Graduated in B.tech Civil Engineering from Kannur University in 2014 and pursuing M.tech in

Coastal and Harbour Engineering from Kerala University of Fisheries and Ocean Studies, Kochi. With one year of teaczhingexperience.

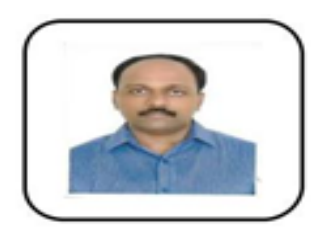

Kiran A S Graduated in B.tech Civil Engineering from college of engineering, Trivandrum (2007) and M.tech,in Geotechnical Engineering from IIT Roorkee (2009). Presently working as Scientist D at National Institute of Ocean Technology,Chennai. Has 9 years of experience in the area of Coastal Engineering. Involved in the design and execution of shore protection projects and execution of various sponsored projects in the area of Coastal Engineering

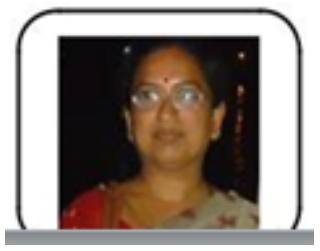

Dr. Vijaya Ravichandran, Scientist-F, Coastal \& Environmental Engineering Group, NIOT.Experience of over 25 years in Ocean related Civil and environmental engineering in coastal infrastructure development. Involved in design, development and deployment of suction pile in offshore waters. Design and field demonstration of submerged dyke using geosynthetics for river siltation prevention works in early 2003 in the Hugli Estuary and presently beach restoration in the Kadalur fishing villages Tamilnadu

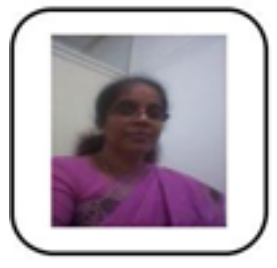

Dr Suriyakala C D Graduated in B.E Electronics \& Communication Engineering 1990 , MS (by research) from Anna University Chennai and Doctoral degree from Sathyabhama University in 2009. With nearly three decades of teaching experience, research experience, more than hundred publications and sponsored research projects added credits to her career. Editor \&Reviewer of premier journals 